\title{
Seeking Information on Social Commerce: An Examination of the Impact of User- and Marketer-generated Content Through an Eye-tracking Study
}

\author{
Patrick Mikalef $^{1} \cdot$ Kshitij Sharma $^{1} \cdot$ Ilias O. Pappas ${ }^{1,2} \cdot$ Michail Giannakos $^{1}$ \\ Published online: 22 June 2020 \\ (C) The Author(s) 2020
}

\begin{abstract}
Following the growing popularity of social commerce sites, there is an increased interest in understanding how consumers decide what products to purchase based on the available information. Consumers nowadays are confronted with the task of assessing marketer-generated (MGC) as well as user-generated information (UGC) in a range of different forms to make informed purchase-related decisions. This study examines the information types and forms that influence consumers in their decisionmaking process on social commerce. Building on uses and gratifications and dual-process theories, we distinguish between marketer and user generated content, and differentiate formats into informational and normative. Using a mixed methods approach that builds on an eye-tracking study, followed by semi-structured interviews with 23 participants, our results indicate significant differences in the types and format of information consumed for selected versus eliminated products. Specifically, we looked at engagement, cognitive processing, and observation of consumers, since they reveal information about the mental and processing mechanisms during decision making. We find that consumers present a number of differences in terms of these measures among the different types of content, and with respect to selected versus eliminated products. The outcomes of the interviews also serve to complement these findings, providing more detailed information about the processes and emotional states of consumers during the selection process.
\end{abstract}

Keywords Eye-tracking $\cdot$ Social commerce $\cdot$ Dual-process theory $\cdot$ User-generated content $\cdot$ Online reviews $\cdot$ Interviews

\section{Introduction}

With the popularity of social media and social networks growing rapidly in the past few years there has been a new subset of e-commerce brought to the spotlight, social commerce (Dwivedi et al. 2018; Kapoor et al. 2018). In contrast with traditional e-commerce outlets, social commerce sites present certain unique characteristics, primarily by facilitating social interactions, as well as the creation and circulation of user generated content (Mikalef et al. 2013). As a result, it is no surprise that social media have attracted major interest from business executives and marketers in relation to their potential

Patrick Mikalef

patrick.mikalef@ntnu.no

1 Department of Computer Science, Norwegian University of Science and Technology, Sem Saelands vei 9, 7034 Trondheim, Norway

2 Department of Information Systems, University of Agder, Universitetsveien 25, 4630 Kristiansand, Norway to generate a competitive edge (Zhou et al. 2013). An increasing number of firms are now launching social commerce initiatives in response to this trend, sparked by several promising early outcomes of business value (Stephen and Toubia 2010; Zheng et al. 2017). Yet, one of the differences of social commerce sites compared to conventional e-commerce portals, is that information about products is no longer created solely by marketers, but a large proportion of this power is now transferred to consumers (Dwivedi et al. 2008). For example, product ratings, consumer reviews, as well as multimedia content can be uploaded on popular social commerce platforms, which complement existing marketer-generated content (Singh et al. 2017). This creates an interesting environment, since potential consumers need to navigate and assess information from both marketers and past consumers before they make purchase-related decisions (Goh et al. 2013). There is, as a result, a breath of information that consumers need to process before making informed purchase-related decisions (Kizgin et al. 2018; Tang et al. 2017).

With user generated content occupying increasingly more weight in the decision-making process of individuals, it has 
emerged as a central topic of research agendas accordingly (Cheung et al. 2009). As consumers are shifting their purchases on the social commerce environment, they are confronted with making purchase-related decisions based on both marketer-generated content and user-generated content. This makes the process by which consumers evaluate and take into account each type of information incrementally complex (Cheong and Morrison 2008). Adding to the complexity is the fact that user-generated content is created from a very large number of unknown participants world-wide, and the presentation of such a vast amount of information makes decision making a complex and messy task (Mikalef et al. 2012). For instance, popular products present on social commerce sites typically have hundreds if not thousands of reviews (Kaushik et al. 2018; Saumya et al. 2018), each of which can range between 100 and 2000 words. In addition, the format that user-generated content is presented to potential customers differs significantly, from extensive text reviews, to aggregated information, keywords, and summarized product ratings (Cheung et al. 2009). These differences in presentation format of product-related information concerns both user-generated content as well as marketer-generated content (Roma and Aloini 2019; Yadav et al. 2013). As a result, the difference in the format of presented product information on social commerce websites leads to different forms information processing by consumers (Yadav et al. 2013; Zhang and Benyoucef 2016). These differences in information processing styles are also likely to take place during different stages of the decisionmaking process (Wang and Yu 2017; Yadav et al. 2013).

Building on this research gap, this study is grounded on uses and gratifications theory and dual-process theory, and attempts to understand what type of information users tend to rely on when faced with a purchase dilemma on social commerce platforms. Uses and gratifications theory is used to understand how consumers utilize information to make purchase-related decisions, while dual process theory is employed to determine how different formats of information presented on social commerce websites can be used to facilitate implicit and explicit processing of this information to guide decisions. We employ a mixed methods approach, which includes an eye-tracking study on a popular social commerce site to identify the differences in information consumption between the products selected compared to those that are omitted, followed by a semi-structured interview with participants. In the research setting we distinguish between two types of information (marketer-generated and user-generated), and two types of information presentation (informational and normative). Following, we define different areas of interest on a popular social commerce site based on these. We first run the eye-tracking study, and through measures of engagement, cognitive processing, and observation find differences in the areas of interest between selected and eliminated products. From the underlying mental mechanisms that support these measures, we deduce several important implications for research and practice. To supplement these findings, we conduct semi-structured interviews with participants directly after their eye-tracking experiment. The outcomes of the interviews serve to provide greater depth to the rationale of the participants on the choice of information and the presentation style, as well as to describe the process through which they reached their purchase decision.

The rest of the paper is structured as follows. In Section 2 we review the theoretical background which this study builds upon. In Section 3, we present our research questions and the associated measures we use to examine them, while in Section 4 the study design is described. Section 5 introduces the analysis and describes with results from the eye-tracking experiment and the semi-structured interviews. In closing, Section 6 discusses the theoretical and practical implications that arise from the results and outlines limitations and directions for future research.

\section{Theoretical Background}

When compared to physical, or even conventional online stores, social commerce sites present a unique mixture of characteristics. Perhaps the major differentiator is that unlike traditional online stores where featured content is solely provided by the marketer or producer of the product (marketergenerated content) (MGC) (Goh et al. 2013), social commerce sites include information that is generated by the consumers themselves, also referred to as user-generated content (UGC) (Van Dijck 2009). The simultaneous presence of both types of content creates an interesting context, since potential consumers have to navigate and make decisions based on both types of information (Cheong and Morrison 2008). While traditionally marketers have been in position to control all product related information on commerce outlets, the affordances that social commerce sites provide, enable consumers to have share their opinions and exert a strong influence about products or services that are advertised, without being bound by standards of objectivity (Bruhn et al. 2012; Muhammad et al. 2018). In this regard, while UGC provides important input for consumers when forming their purchaserelated decisions, the presence of negative content towards a product can have harmful consequences for building and maintaining a brands image for marketers. This issue is compounded since consumers rely to an increasing extent on UGC when making purchase decisions (Luo et al. 2013). While UGC has dominated research attention in the emergence of social commerce, there are very few studies that examine how consumers make decisions under the simultaneous presence of both UGC and MGC. In addition, the effect that information formats have on consumer decision-making is seldom examined (Trusov et al. 2009). 
To explore these topics and to examine the perceived value of each type and format of information, we build on the uses and gratification theory (UGT). Uses and gratification theory is concerned with how individuals utilize media, and how their needs are fulfilled by specific aspects of these media, thus, centering on the individual as the main unit of analysis (Plume and Slade 2018; Ruggiero 2000). The theory has been applied extensively in online environments since it provides one of the most coherent perspectives in explaining the psychological and behavioral dimensions in mediated communications (Ko et al. 2005). The main application of uses and gratifications theory is to provide an explanation regarding the psychological needs that shape why people use media, and what stimuli lead individuals to engage in specific media-based behaviors (Ko et al. 2005). Uses and gratification theory builds on the assumptions that users are goal-oriented, and as a result, when they are faced with a decision choice they select the appropriate media to gratify their goals or needs (Limayem and Cheung 2011). In the domain of social commerce studies, UGT has been one of the core theoretical perspectives in explaining the motives, beliefs, and values of consumers (Mikalef et al. 2013; Tsai and Men 2017). Despite UGT been mostly applied on explaining the extent of use of certain affordances on social commerce websites, there is still very little empirical research with regard to the consumption of information that originates from different types of sources.

In addition, the format in which these information sources are examined is commonly categorized into either UGC or MGC. Nevertheless, the vast majority social commerce sites present both types of information in a number of different formats. These different formats lead to different ways of consumptions by customers when they are in the process of forming the purchase decisions. Dual-process theory has been a widely applied theory to explain how people are influenced by the different forms of information they are provided with (Cheung and Thadani 2012). When applied to the context of online shopping, dual-process theory has been employed to differentiate between two main types of information formats, normative factors and informational factors (Filieri 2015). Normative factors include social aggregation mechanisms available on social commerce websites and are commonly represented as crowd opinion information such as overall product score and customer ratings. The overall product score is generally displayed by the number of stars or by an overall numeric score which represents the average rating provided by other customers. On the other hand, informational factors are based on the content of user experiences or marketer descriptions and are associated with the quality of information and the perceived credibility of the source. The main idea on which dual-process theory builds on in the context of online information seeking, is that informational and normative factors work in parallel in shaping consumers opinions about products they see online, and when making purchase-related decisions (Cheung and Thadani 2012). In the current study, dual-process theory is used as the theoretical grounding to explain the extent to which these two types of information influence the purchase decisions of users of social commerce websites. As such, it provides an influence model based on both the consumers' self-judgment of the information provided by marketers and consumers, and the normative power of aggregated information. Informational influence is derived from information obtained as evidence about reality, and therefore is present in the content, source, and visual cues relating to the product at hand, whether UGC or MGC. On the other hand, normative influence is apparent in aggregated evaluations of the opinions of others (Filieri 2015).

When looking into specific informational factors and their components, Yale's model distinguishes between, source, message, and receiver (Cheung et al. 2009). Within the message component, product related information such as description, price, and technical characteristics are important elements, while visual cues such as pictures of the product are also found to play a significant role in communication judgment in terms of MGC (Wells et al. 2011). Other studies have also noted that thumbnail images tend to produce additional stimuli to consumers, who engage in the activity of enlarging them to located more detailed visual information about the product and increase their enjoyment (Kim et al. 2007). Nevertheless, are increasingly relying on UGC to get more information about a product they are interested in, and examine in detail descriptions and evaluation about experiences of other consumers (Kim and Srivastava 2007). In many cases UGC is used to supplement MGC and aid consumer decision-making. Specifically, much research has looked at reviews made by other consumers, since their content, whether positive or negative, has been shown to have a significant influence on intentions to purchase (Zhang 2005). Apart from the importance of such informational components in decision making, consumers rely heavily on the aggregated opinions of masses, making normative factors such as average product scores or ratings, an easily understandable resource on which they can anchor their decisions (Flanagin et al. 2014). Therefore, UGC is most frequently represented through informational and normative formats. In conclusions, we regard the previously mentioned informational and normative factors as important determinants of consumers' intention to make purchaserelated decisions on social commerce websites. Prior literature has examines their isolated impact on shaping consumer intentions, but has attributed much less attention on how their simultaneous presence shapes consumer decision-making.

\subsection{Informational Factors}

When considering information factors on social commerce websites, these typically involve both types of sources, UGC and MGC. With regards to marketer-generated content, this 
usually is presented in similar way across social commerce vendors. Specifically, price is an important component and informational factor when it comes down to any purchase decision. Consumers develop their perceptions of value of a product in relation to both characteristics and through an assessment of the price/characteristic ratio. The combination of price with brand recognition has also been shown to mitigate perceptions of risk as well as influence consumers cognizance about product quality (Flanagin et al. 2014). In online settings such as those of social commerce sites, it has been suggested that the presence of additional informational factors related to the product can help consumers avoid risky purchases and facilitate the process of making decision about what product to buy (Chiu et al. 2014). Recent empirical findings from Chen et al. (2016), show that the availability of information in a multitude of formats can has a positive contribution towards intentions of consumers to purchase online. This outcome demonstrates that consumers are inclined to go through many different types of information from which they form a complete pictues of the product they are interested in. Yet, product-related information may be presented in a number of different formats. A particularly influential format is through images of the product itself. Pictures of the product have been found in past empirical work to evoke different levels of emotional imagery (Flores et al. 2014). Building on this knowledge, Yoo and Kim (2014) show that the capacity to interact with visual cues, such as zooming into the product or enlarging a thumbnail, has a significant effect on consumers buying-related behavior. Hence, we can conclude that the way consumers interact with marketer-generated content can say a lot about whether they intend to purchase a product or not. Such differences in behavior can be observed also in terms of the information they consume when attempting to make a decision (Kim and Lennon 2008).

While marketer generated content has been the conventional source of information that consumers utilize when assessing product they are interested in, user generated content has gradually claimed an increasingly important part on social commerce sites, and as a result largely influences the decisionmaking process (Cheong and Morrison 2008). User generated content can range from negative reviews to highly positive, and has been the focus of much research attention over the past few years (Chevalier and Mayzlin 2006; Zhu and Zhang 2010). However, research outcomes are ambivalent on how consumers factor both positive and negative reviews when trying to form a purchase-related decision on social commerce sites (Dhar and Chang 2009). Chevalier and Mayzlin (2006) found that products that had more positive user generated content also presented higher sales, although the effect of negative user generated content on sales was much stronger. Similar findings have also been observed in other studies in which more positive user generated content resulted in increased sales (Forman et al. 2008). On the other hand, the presence of negative product reviews can also help consumers make purchase decision, since they most commonly serve as the basis on which they can detect and eliminate low quality or undesirable products (Lee et al. 2008). Thus, positive and negative reviews play a different, but equally important, role in shaping consumers intentions of which products to select.

\subsection{Normative Factors}

Despite the contributing effect that informational determinants have on shaping consumers behavior, they can only in part explain how consumers assess and evaluate products browsed online. In many cases the presence of normative factors helps to aid decision making and filter out products on help prioritize them (Liang and Turban 2011). On most social commerce websites, a range of different representation mechanisms are available which are aimed at structuring and visually aggregating the opinions and perceptions of past buyers. Product ratings are a typical such measure, which most commonly calculate the mean score given to a specific product by all past buyers. In most cases, these scores are represented in a 5-level scale, either as a numerical value or in the form of a star rating system. Some social commerce websites also allow representation through which consumers can see the number, or percentage of consumers who rated the product on each score (i.e. how many gave it a score of 1 out of 5, 2 out of 5 etc.). Other popular means of depicting normative information to consumers are by showing the number of consumers who find a review helpful and informative, thus providing a form validity to certain high or low rated reviews. These forms of representing aggregated user attitudes and beliefs are some of the most influential when it comes to decision making (Forman et al. 2008). Previous research has shown that normative factors such as user-generated product ratings, influence consumers perceptions of product quality, which in sequence has an impact on purchase decisions (Flanagin et al. 2014). In the area of online hotel bookings Ye et al. (2011), found that a $10 \%$ increase in traveler review ratings, can have a significant impact on sales, by boosting online bookings by more than 5\%. All these prior findings in the context of social commerce highlight the importance that normative factors have in the decision-making process (Flanagin and Metzger 2013).

\subsection{Neurophysiological Perspectives in Social Commerce Research}

During the past few decades there has been a rapid advancement in terms of technological and theoretical knowledge about neuroscience, neurocognitive and neuropsychological methodologies, particularly in relation to understanding how consumers engage in tasks and perform decision making activities. More specifically, eye-tracking has been an essential 
part of identifying interactions between humans and online interfaces, and it is a well-suited method to capture how specific visual stimuli influence eye movements, which can then be utilized to discover consumer strategies and to understand the underlying cognitive processing (Luan et al. 2016). According to Jacob and Karn (2003), eye movement and pupil dilation can reveal human perceptual, emotional, and cognitive processes, helping to further predict and interpret human behavior. These associations between eye movement and pupil dilation, and cognitive processes have served as the basis for much work in other fields such as behavioral economics and psychology (Mele and Federici 2012).

The value of adopting neurophysiological methods has been argued over the past ten years in information systems (IS) research, with several seminal papers demonstrating optimal ways of adopting such methods in the IS context (Dimoka et al. 2012). The value of applying such methods in IS domain lies primarily in the fact that such methods can capture underlying non-conscious processes or actions, that are not directly observable by participants (de Guinea et al. 2014). Capturing such processes, particularly in the context of social commerce which is rich with information of different types and formats is of high importance, as most studies to date utilize surveys or interviews to understand how consumers interact and experience such mediums (Zhang and Benyoucef 2016). By understanding the cognitive states that are sparked when accessing different informational queues during social commerce browsing, and gaining a detailed temporal sequence of events, it is possible to understand the "journey" consumers go through when attempting to make informed decision about what products they should purchase. Analyzing such data can also pinpoint to types or formats of information that generate confusion, information overload, spark attention, or facilitate cognitive ease (Léger et al. 2014). In turn, knowing how social commerce websites spark specific cognitive states, and the journey through which users consume information, can be used by designers to optimize design and presentation of information, as well as develop ways of visualizing information that make it easier for consumers to reach a conclusion about their purchase (Dimoka et al. 2011).

\section{Research Approach}

The present study follows an exploratory approach and aims to understand how users interact with the different types and formats on information available on social commerce sites. Gaining deeper knowledge about what types and formats consumers use, and the sequence that this is done can help us understand more about the decision-making process when selecting a product to purchase. Our research approach includes a mixed-methods analysis, in which we first start by conducting eye-tracking experiments with a group of social commerce users, followed by semi-structured interviews. The following sub-sections describe the method used in each and the key measures.

In relation to the eye-tracking experiment, we use several different measures that are associated with distinct cognitive mechanisms. These measures allow us to understand how users interact with content, and ultimately the parts they emphasize on in each stage of their decision-making process. Consequently, we distinguish between three types of processing which can be identified through an eye-tracking study, engagement, cognitive processioning, and observation (Mikalef et al. 2017a, b, c). These types of processing are also the main measures used in our study. Eye-tracking can capture the dilation of pupils, as well as movements or transitions, as well as areas of focus (Nyström et al. 2016).

Engagement was gauged by looking at the peak velocity of transitions between two areas of interest. Human eyes cannot travel faster than a biological upper limit of their velocity (Salvucci and Goldberg 2000). When moving from one point of interest to another, the eyes have to accelerate and decelerate. This means that at a certain time during this transition the eyes attain their highest velocity. Peak saccadic velocity is often measured as the percent of the saccade length when the maximum velocity was reached (Duchowski 2007). This measure has been linked reversely with a user's level of engagement (McGregor and Stern 1996). This indicates that the faster the eyes attain the maximum velocity (which will return a lower value in terms of percent of length of the saccade) the more the user is engaged. Therefore, engagement can be measured through peak saccadic velocity, with higher levels of the former being represented through lower levels of the later.

Cognitive processing was assessed by looking at the pupil dilation. The pupil diameter is regarded as the proxy of the mental activity, or in other words, a measure of the depth of cognitive processing of individuals during a specific task (Kahneman et al. 1969). In relation to the dual-process theory, Kahneman et al. (1969) found that an increased pupil size is associated with high mental activity, an indication of enhanced cognitive function load (Croson et al. 2013). Lower pupil diameters are an indication of more load on working memory and faster calculations. When computing the rate of change of these functions it is possible to calculate task difficulty, and thus measure the degree of deep cognitive processing. Nevertheless, since pupil diameter can be sensitive to many external factors which are independent of experimental conditions (for example, age, sleep-conditions, use of substances like caffeine, nicotine, and medication) we normalized the pupil diameter with respect to the first five seconds of data to remove the effects of external variables.

Careful observation refers to the average period of time during which the gaze of individuals is relatively stable over a relatively longer period of time measured in milliseconds. This measure is associated with careful investigation of the stimulus, meaning that there is increased attention on the 
object of focus. Just and Carpenter (1980) proposed an eyemind hypothesis, stating that there is no substantial lag between what we fixate on and what we process, which has been widely supported by previous studies in different tasks, such as reading and scene perception (Engbert et al. 2005). Careful observation in the shopping context essentially denotes that the consumer is performing local processing on the information type and format. This is in contrast to global processing of the whole page to find relevant information for his purchase which is more related to browsing.

Building on the different types of information and the formats they are presented in we present the following research questions that we aim to answer in the eye-tracking study:

RQ1: Are there differences in terms of engagement, cognitive processing, and observation of information found on social commerce websites when making purchaserelated decisions?

RQ2: How do these differ based on the type and format of the information presented to consumers?

RQ3: What can we deduce from these differences based on the distinction between products consumers will select compared to those they eliminate?

Following the eye-tracking, the next stage involved conducting interviews with participants. The questions of the interview are based on the previously described types of information and their format of presentation. The goal of the interview was to examine in more depth the process that participants went through when trying to decide which product to purchase. While eye-tracking was the main tool for investigating behaviors of interaction on social commerce sites, interviews allowed us to understand the emotional and cognitive processes that participants underwent when trying to decide what product to select. The questions that were posed to participants were based on a semi-structured interview, and were conducted by two of the co-authors directly after their eyetracking session. The main research question that we tried to examine in the interviews was the following:

How is information on social commerce websites consumed to make decisions? What is the process that is followed to select a product when faced with a purchase-related choice?

\section{Method}

\subsection{Participants and Procedure}

For the purpose of this study, 23 participants were recruited using a random selection procedure so as to ensure that we had sufficient diversity within our group. All of the participants had been screened so we made should they had normal or correct-to-normal vision. The sample was divided almost equally between males (13) and females (10), with the average age being 27.5 years (age std. dev. 7.15 years). We selected Amazon.com as the social commerce website to run our experiments, since it was most likely that participants would have experience and would be familiar with all sources of information provided. All participants had average to high experience with shopping at Amazon. During the task, participants were provided with three Amazon products (electronic fans with remote controls). The products were chosen to be gender neutral so that the gender bias could be eliminated as it has been shown that certain types result in discrepancies between the two genders (Lin et al. 2019). The simple experimental task was to select one fan out a pre-defined selection of 3 , after carefully examining the information given on each of the pages. On average, participants took $10-15 \mathrm{~min}$ to decide which product they would prefer to buy. During this process, their gaze was recorded using three SMI eye-tracking glasses at $60 \mathrm{~Hz}$ and two Tobii eye-tracking glasses also at $60 \mathrm{~Hz}$. The experiments took place between October and November 2016 in setting that can be seen in Fig. 1 below. Before each participant started the experiment, the eye-trackers were calibrated with markers positioned on the corners of the screen in order to accurately capture gaze location. Participants were also asked to refrain from taking to each other, and to keep their focus as much as possible on the screen.

\subsection{Variables}

As the dependent variable of this study, we selected a binary variable representing the selection or not of a product. Therefore, we differentiated between two values, selected products that were represented with 1 , and eliminated ones which were represented with a value of 0 . As part of the process variables, we calculated three different measures, as described in the previous section. These included engagement, cognitive processing, and observation. Engagement was measured by measuring peak saccadic velocity, with high engagement being represented through a low peak saccadic velocity (Di Stasi et al. 2013). This measure was calculated within each of the pre-defined information types formats that were described in the theoretical background section. Cognitive processing was measured by examining dilation of pupil size (Hyönä et al. 1995). A low pupil size is indicative of deeper cognitive processing. Finally, observation was assessed as the mean period of time in which the gaze is stable (Priebe et al. 2015). Careful observation was gauged through a measure of high fixation duration mean, and low fixation duration variance. These measures were calculated from output produced by the software that supports the Tobii eye-tracker, combined with some custom code. We utilized the software of the eyetracking device manufacturer, as well as IBM SPSS 25.0 to analyze the data. 
Fig. 1 Experiment set-up with mobile eye-trackers

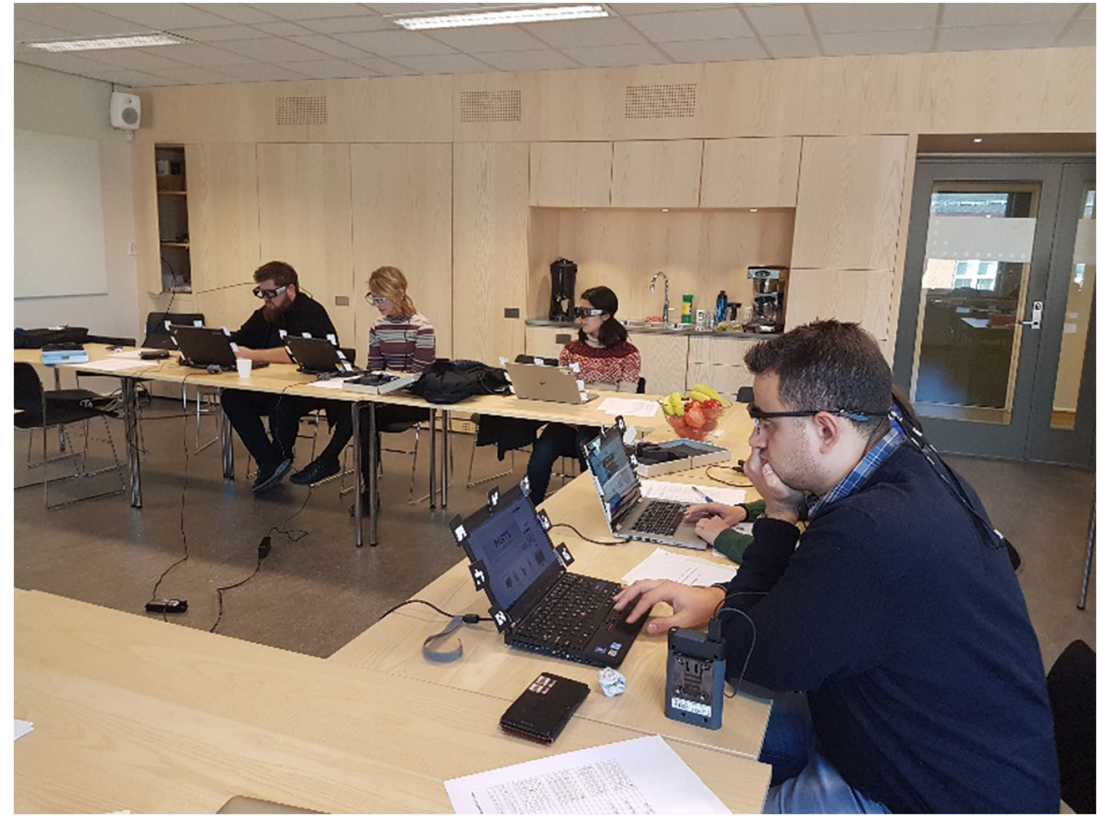

\subsection{Areas of Interest}

The product page of Amazon was divided into eight different areas of interest as can be depicted in Fig. 2 below. These include (a) product details, (b) product description, (c) specification table, (d) review summary, (e) negative reviews, (f) positive reviews, (g) image, and (h) zoomed image. From these areas of interest $\mathrm{a}, \mathrm{b}, \mathrm{c}, \mathrm{g}$ and $\mathrm{h}$ represent marketergenerated content, while areas d, e and f user-generated content. In addition, area $\mathrm{d}$ represents normative information since aggregate scores are shown on mean product value from past consumers, as well as proportion of users that have given each of the 5 scores.

\subsection{Interviews}

Interviews followed a semi-structured protocol in which participants where asked several questions about how they made their decisions, what information they looked at, what influenced them most, if and how they eliminated products, and other aspects that they took into account when making their decision. In addition, several questions about their experience in using social commerce sites and the types of products the typically buy were asked. Interviews were recorded with the consent of participants, and on average lasted $47 \mathrm{~min}$. During this time, we tried to uncover the process that users went through in order to reach a decision without indicating any specific type of information type. After the completion of the interviews we asked participants their impression of the process and if they had any suggestion to improve the setting. All recorded interviews were transcribed, and kept in a file with notes made during the interview by the co-authors.
The empirical data analysis was done through an iterative process of reading, coding, and interpreting the transcribed interviews and observation notes of the 23 interviews (Myers and Newman 2007). At the first stage of our analysis we identified and isolated the information types and sources on the basis of the predefined formats as discussed in the earlier sections. For each case the standardization method was used to quantify these characteristics using an open coding scheme (Yin 2017). In addition, we recorded the process that participants went through in order to reach a conclusion, and the types of information they noted as important in doing so. Two of the co-authors completed the independent coding of the transcripts in accordance with the defined themes as discussed in the previous sections. Each coder read the transcripts independently to find specific factors related to the important information factors, as well as on the steps in reaching a purchase decision. This process was repeated until inter-rater reliability of the two coders was greater than 90 percent (Boudreau et al., 2001).

\section{Results}

To analyze the outcomes of the eye-tracking study, we conducted two-tailed t-tests to compare the above-mentioned variables (i.e. engagement, cognitive processing, and observation) across the products which were bought or eliminated. The test results means and standard deviation for all the variables are presented in the tables below. Significance levels were estimated using a two-tailed test, where $p<0.05$ is the lower threshold where we identify statistical significance. Prior to the analysis all data were subjected to normality tests 

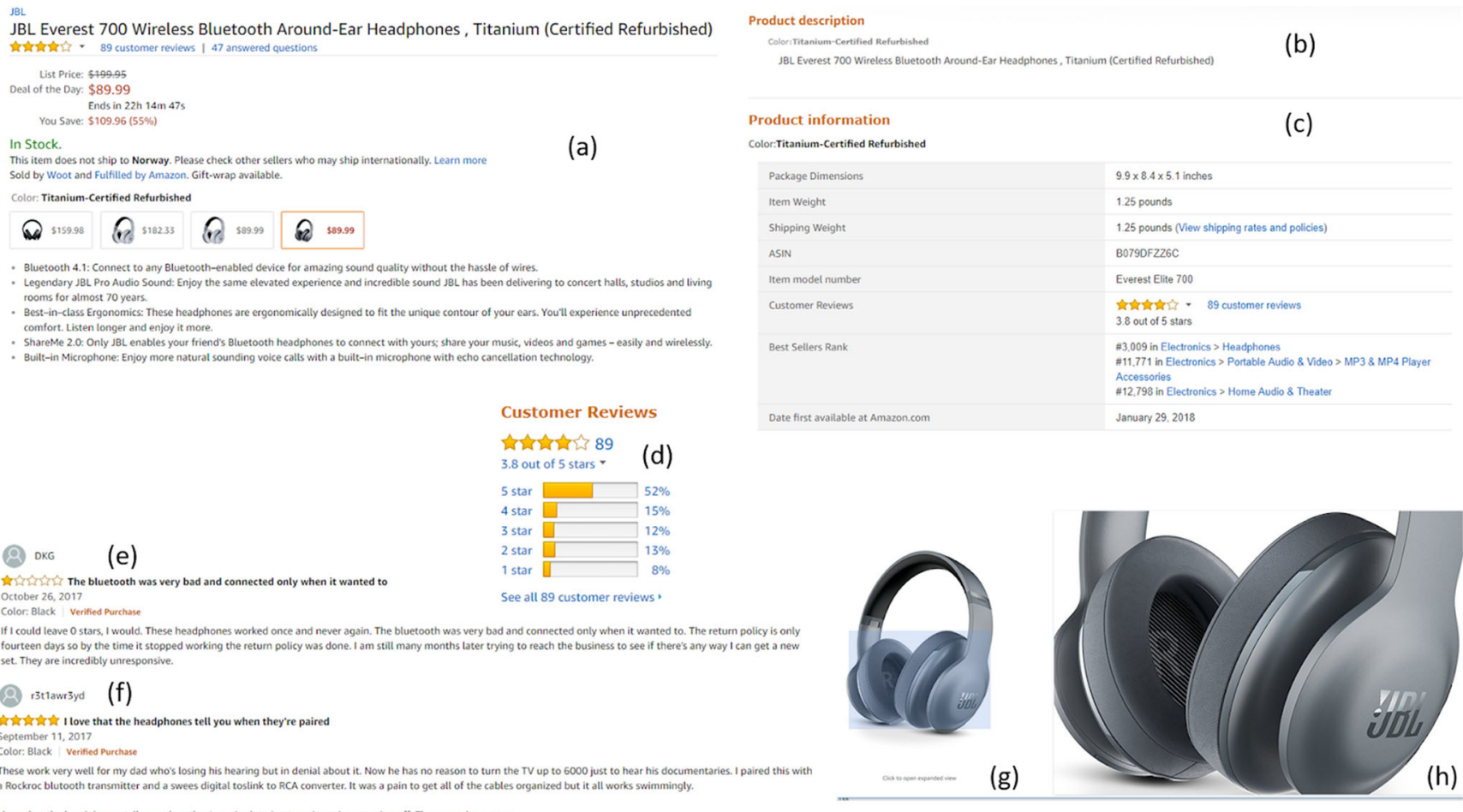

Fig. 2 Areas-Of-Interests (AOIs) defined for the analysis of the eye-tracking data

using both, the Kolmogorov-Smirnov, and Shapiro-Wilk tests (Lilliefors 1967; Shapiro and Francia 1972). The results indicate that the data follow a normal distribution.

\subsection{Engagement}

Regarding engagement, the peak saccadic velocity during the moments that participants were looking at the image of the product and the zoomed image was lower for the bought product than that for the eliminated products (Table 1). The outcomes of previous eye-tracking studies show that the peak saccadic velocity could be used as a proxy for engagement patterns (Di Stasi et al. 2013). Our findings show that the engagement with the product image (and the zoomed version of it) is higher for the bought product than the eliminated products. This significant difference is magnified when consumers looked into the zoomed image, which denotes a stronger mental workload to extract useful information that can help them make a purchase decision. Furthermore, the results confirm that visual cues are very important when trying to attract consumers attention. Also, the fact that consumers are more engaged on selected products than eliminated one's hints that they use these images either to verify their choice, or are just more attracted to these products at the first place, and use other information to justify their selection. It also could hint that aesthetics, that are not easily described in other formats play a key role not only in the design of the platforms themselves (Pappas et al. 2018), but also to the selection process.
Table 1 Comparison of engagement (peak saccadic velocity $\%$ ) for the selected and eliminated products

\begin{tabular}{lllll}
\hline AOI & $\begin{array}{l}\text { Selected } \\
\text { Mean (Std. dev) }\end{array}$ & $\begin{array}{l}\text { Eliminated } \\
\text { Mean (Std. dev) }\end{array}$ & $\begin{array}{l}\text { T-test } \\
\text { statistic }\end{array}$ & $p$-value \\
\hline a) Product details & $17.54(20.60)$ & $17.93(22.21)$ & -0.05 & 0.95 \\
b) Product description & $14.51(26.75)$ & $11.98(21.60)$ & 0.31 & 0.75 \\
c) Specification table & $7.00(24.96)$ & $12.62(24.00)$ & -0.70 & 0.48 \\
d) Review summary & $29.69(18.99)$ & $26.05(16.48)$ & 0.03 & 0.53 \\
e) Negative reviews & $23.63(11.43)$ & $30.87(15.22)$ & -1.65 & 0.11 \\
f) Positive reviews & $15.68(21.06)$ & $21.31(18.75)$ & -0.87 & 0.38 \\
g) Image & $23.98(10.53)$ & $38.96(20.84)$ & -2.79 & $0.009^{* * *}$ \\
h) Zoomed image & $23.21(9.31)$ & $37.06(20.10)$ & -2.72 & $0.01^{* *}$ \\
\hline
\end{tabular}

Note: $* p<0.05, * * p<0.01, * * * p<0.001-$ decimals were rounded up, that is why $p$-values of 0.01 appear with two asterisks 
Table 2 Comparison of cognitive processing (pupil diameter change) selected and eliminated products

\begin{tabular}{lllll}
\hline AOI & $\begin{array}{l}\text { Selected } \\
\text { Mean (Std. dev) }\end{array}$ & $\begin{array}{l}\text { Eliminated } \\
\text { Mean (Std. dev) }\end{array}$ & $\begin{array}{l}\text { T-test } \\
\text { statistic }\end{array}$ & $p$-value \\
\hline a) Product details & $0.66(0.78)$ & $0.33(0.87)$ & 1.22 & 0.22 \\
b) Product description & $0.49(0.80)$ & $0.68(0.51)$ & -0.88 & 0.38 \\
c) Specification table & $0.45(0.68)$ & $0.56(0.44)$ & -0.59 & 0.55 \\
d) Review summary & $0.01(0.78)$ & $0.63(0.60)$ & -2.71 & $0.01^{* *}$ \\
e) Negative reviews & $0.12(0.76)$ & $0.78(0.50)$ & -3.13 & $0.003^{* *}$ \\
f) Positive reviews & $0.24(0.34)$ & $0.69(0.34)$ & -2.70 & $0.01^{* *}$ \\
g) Image & $0.26(0.58)$ & $0.32(0.67)$ & -0.32 & 0.74 \\
h) Zoomed image & $0.52(0.63)$ & $0.46(0.58)$ & -0.33 & 0.74 \\
\hline
\end{tabular}

Note: $* p<0.05, * * p<0.01, * * * p<0.001-$ decimals were rounded up, that is why $p$-values of 0.01 appear with two asterisks

\section{Cognitive Processing}

When assessing the cognitive processing of participants, we found several differences between those products that were eliminated compared to the selected ones (Table 2). The pupil diameter during the moments when the participants were looking at the reviews section of the page (review summary, negative and positive reviews) was lower for the bought products than that for the eliminated products. The pupil diameter has been shown to be associated to the level of mental processing and the load on the working memory. In other words, the pupil diameter is related to the cognitive processing participants put across while they are observing a visual stimulus. Our results indicate that the participants were involved in a deeper cognitive processing of the reviews of the bought products than those of the eliminated products. These findings indicate that before finalizing their choice, consumers tend to look at specific types of information, but mostly rely on UGC in lengthy descriptions. These reviews are then used to verify choices (positive) as well as avoid risky purchases (negative). This tactic demonstrates that there are two opposing strategies consumers undertake on the one had to reduce stress by confirming positive view of the product, but also examining negative ones to avoid purchases that would be considered risky. When associated with the metric we used, that is cognitive processing, we see that participants undergo a series of different processes that can be better captures through alternative means.

\subsection{Observation}

When examining the observation patterns of participants, we found several key differences in many types and formats of information (Table 3). The mean fixation duration during the moments when the participants were looking at the specification table and the reviews section of the page (review summary, negative and positive reviews) was lower for the bought products than that for the eliminated products. The fixation duration has been shown to be indicative of careful observation of the stimulus. Our results indicate that the participants observed more carefully the specification table and the reviews section of the bought products than those of the eliminated products. This outcome shows that when assessing which products to buy, in types such as the ones we presented them with,
Table 3 Comparison of observation (mean time that gaze is stable) for selected and eliminated products

\begin{tabular}{lllll}
\hline AOI & $\begin{array}{l}\text { Selected } \\
\text { Mean (Std. dev) }\end{array}$ & $\begin{array}{l}\text { Eliminated } \\
\text { Mean (Std. dev) }\end{array}$ & $\begin{array}{l}\text { T-test } \\
\text { statistic }\end{array}$ & $p$-value \\
\hline a) Product details & $168.15(60.25)$ & $183.18(46.17)$ & -0.84 & 0.40 \\
b) Product description & $176.13(68.07)$ & $171.13(46.97)$ & 0.79 & 0.79 \\
c) Specification table & $195.68(51.27)$ & $150.67(47.55)$ & 2.81 & $0.008^{* *}$ \\
d) Review summary & $190.19(51.61)$ & $139.58(41.97)$ & 3.01 & $0.002^{* *}$ \\
e) Negative reviews & $187.40(45.34)$ & $138.63(62.02)$ & 2.76 & $0.009^{* *}$ \\
f) Positive reviews & $198.63(48.95)$ & $141.98(34.87)$ & 4.01 & $0.0002^{* * *}$ \\
g) Image & $173.63(46.46)$ & $176.11(56.96)$ & -0.14 & 0.88 \\
h) Zoomed image & $191.89(55.02)$ & $178.77(64.07)$ & 0.67 & 0.50 \\
\hline
\end{tabular}

Note: $* p<0.05, * * p<0.01, * * * p<0.001-$ decimals were rounded up, that is why $p$-values of 0.01 appear with two asterisks 
which have more utilitarian purpose than hedonic one, product characteristics are important. The finding also shows that positive and negative reviews are used to eliminate products, since there are higher observation rates in those that were not selected. It is quite typical for consumers to look at reviews in order to justify the exclusion of specific products. Nevertheless, such findings could differ depending on the types of product.

\subsection{Interviews}

While the eye-tracking study provided some information that is hard to capture through other means, such as surveys, the conducted interviews helped us get a better understanding about how these results can be interpreted and what implications they have. Specifically, we asked respondents to describe the steps they took in selecting the products they did. Here participants showed a largely similar way of processing information, with the first step involving briefly looking at the product ratings, price, and images. Participants noted that an easy way to filter out the top candidates was to compare average ratings, number of ratings, and percentages in each score. More specifically, a participant noted the following:

\begin{abstract}
"What I did was I first looked at the average scores....these were rather similar but I noticed that one of them had much more reviews than the others....when scores are similar I tend to trust the opinion of the mass... in this case there were only three products so I had a look at the price which was more or less the same, and then went through to the percentages of scores...here things started to tilt towards one"
\end{abstract}

Our results also show after this initial screening, participants look at other information such as that in the product description, table of characteristics, as well as some positive and negative reviews. During this second phase, there is a higher cognitive processing and a more detailed look at features of the product, as well as experiences of other buyers. One of the participants noted the following:

"I take some time to compare products between them....I like to know the technical details and I find that there is much to read before making any decision...the higher the price, the more time I usually spend...I also look to find stories from other people....I don't like to read reviews that contain information about the product, but more how it was used and what the feeling....when I do that I find that I get what I am looking for"

Some respondents also commented on how they process reviews, and how these reviews affect their decisions. Here we saw a pattern in which negative reviews are used quite extensively to anchor decisions of elimination. This means that consumers tend to go through negative reviews in order to identify major faults with products, and disregard those that have presented defects for others. The number of times faults have been reported, as well as the severity of the fault were deciding factors when choosing which products would be excluded. Contrarily, positive reviews were referenced by participants in order to validate their decisions. In other words, if consumers felt positively about a product, they would try to find information in the positive reviews that reinforced these thoughts. One participant commented the following on this:

"When I want to get a more detailed perspective of products I look at reviews....I like what Amazon does and presents featured negative and positive reviews....these help me a lot......when I have many products and I have to decide which one to pick I first start with the negative reviews....quickly go through 2 3 reviews and the ones that have the most shocking stories are automatically removed from my list...when there are a few left I go into a more detailed look at positive and negative review....it also helps me to examine the specification of products...I do that quite a lot when buying electronics"

In addition to these, some participants noted that when they have to buy a product that is particularly expensive or complex, they tend to visit third-party websites that have a specific focus on reviewing products. These include other websites, as well as YouTube reviews so they can get a better view of products in real-time operation, and a more comprehensive understanding of what they look like. Such responses were from the more experienced social commerce buyers, who also purchased more expensive products online. This finding shows that third-party reviewers are oftentimes considered as more trustworthy compared to those that comment on social commerce sites. As trust has been found to be an important component of facilitating purchase-related decisions, this is an interesting point that could not have eluded us through the eye-tracking approach (Pappas et al. 2017). In addition, the capacity to view products in video, operating live is a type of informational cue that is important for specific product categories.

\section{Discussion}

We presented the results from 23 participants deciding over three products from a popular social commerce setting. The participants were presented with product information of both MGC (title, price, image, details, product info. table) and UGC (positive and negative reviews). The information presented on the Amazon pages for the three products was also be divided in informative (MGC and UGC) and normative (review summary) factors. Through a mixed methods approach 
that combined eye-tracking and semi-structured interviews we measured three different values, namely engagement, cognitive processing, and careful observation, and examined the process through which consumers makes their purchase decision when faced with such diverse information. While this study is not the first to investigate the significance of UGC and MGC on social commerce sites, it is one of the only ones that looks at how consumers interact with both types of information using a novel approach, namely eye-tracking. Also. the fact that we differentiate information types into informational and normative, makes a link to cognitive processing styles, which raises several new question for future research using appropriate methodologies. The outcomes of our analysis present a number of interesting research and practical implications which are described below.

\subsection{Implications for Research}

From a research point of view, this study is one of the first to utilize an eye-tracking methodology to examine the differences in utilization of MGC and UGC during a purchaserelated decision. This is an important extension to the existing body of research in social commerce, as it allows for a more precise understanding of the role of information presented on social commerce outlets, and how it influences conscious and non-conscious cognitive states of consumers. By doing so, we are able to open up new avenues for research on how to present information that facilitates easy and informed decisionmaking when buying online, as well as how to design information presentation schemes to allow for easier consumption of information. Our findings pinpoint towards several differences based on the used measures which hint towards difference in cognitive processing and the series of events that lead to a decision. Specifically, high engagement in a product only differs when looking at images and zoomed images since for all other areas of interest they are found to have no significant difference. It is therefore important to understand the value that visual cues have when deciding on a product, and specifically being able to see details. The results of the interview also suggest that visual stimuli are particularly important, and that is why consumers tend to visit online review sites that feature videos of the products. It is therefore interesting to examine the details of information presented in videos, and extend eye-tracking and cognitive processes examinations of consumers when watching such videos.

In addition, cognitive processing and observation show complementary results. Specifically, they demonstrate that reviews are not considered equally for consumers, but rather, for the selected ones more cognitive load and careful observation is spent for all types of information, normative (review table) as well as informational (positive and negative reviews). These findings when supplemented by interviews show that they are used as a verification tool to establish that the one they have selected is indeed the best option. Thus, confirming opinions through positive reviews and mitigating risk by carefully evaluating negative reviews can increase their belief that the product they have selected is indeed the best (Mikalef et al. 2017a, b, c). Nevertheless, such patterns are contingent on the type and price of product. Our participants noted that when the complexity of products increased they tend to rely more on information that marketers provide in order to have a more comprehensive view. This information when structured appropriately, such as in the format of easily comparable tables, allows for less cognitive effort and an easier selection of the ones that are deemed as more appropriate.

While past research using quantitative methods has confirmed the importance of review in forming purchase-related decisions, the physiological data that eye-tracking methods allow enable us to understand the mental processing that is associated with interactions to the content of social media (Mikalef et al. 2016, 2017a, b, c). The outcomes of the interview also help us determine the sequence of events, and through what information consumers go through when faced with many options and only one choice. While there are some differences between consumers, the type of information and the sequence in which it is processed is quite similar. This of course invites further research, particularly when taking into account different website layouts, products of different characteristics and price, and consumers with different levels of experience.

\subsection{Implications for Practice}

From a practical point of view the outcomes of this study raise a number of implications for marketers of products and social commerce vendors. The first has to do with the affordances that are facilitated in terms of visual cues. Our findings show that consumers engage much more with images of selected products than those that are omitted. While it is not known if this is done unconsciously when forming initial impressions, or after a decision has been made to confirm that decision, the significance of allowing for such interactions with the product are evident. The fact that several participants also noted that video reviews helped them make decisions highlights the significance of adding more content. To date, while most social commerce sites have images of products, few have videos demonstrating the use of products. Similarly, incorporating different forms of user generated content and providing incentives towards past consumers to give feedback is important, since reviews and product summary scores are used to build trust and confirm purchase decisions. The absence of such affordances may lead consumers to third party sites or other vendors. An interesting addition would be to encourage trusted reviewers to create profiles and be able to advertise themselves. Platforms such as YouTube allow third-party reviews to do so as views are a form of digital currency that they 
can utilize. Similar incentives would be interesting to see for social commerce platforms, or at least an integration with some prominent reviewers or third-party sites.

\subsection{Limitations and Future Research}

Despite the novelty of findings, there are certain limitations that characterize our study. First, we do not track the sequence of events that happen in respect to gaze activity. Further studies are needed to examine how the process of deciding unfolds, and the stages through which consumers go through when making a decision. This can be done by analyzing patterns of gaze events through time, and seeing where consumers focus their attention on as time unfolds. Second, we do not control for different characteristics of products, such as price and complexity. It is highly probable that when these aspects are factored in the importance of some areas of interest may change relative to others. When price or complexity rises, it is likely that consumers will use more information, and will go through this information in more detail. Third, a study in which we can monitor the cognitive processes of participants and link these with specific eye-movements would tell us a lot about the cognitive states that they undergo when going through information. Such a study could be done using a combined eye-tracking and electroencephalography method. While this method presents some complexity and ambiguity, a promising way to perform such an analyses would be through the use of wearable systems, as demonstrated by Vourvopoulos et al. (2019). Finally, creating a real-life scenario where consumers have to spend their own money to purchase product could produce slightly different results. The stress of using own resources could magnify the differences in using some information compared to others.

Funding Information Open Access funding provided by NTNU Norwegian University of Science and Technology (incl St. Olavs Hospital - Trondheim University Hospital).

Open Access This article is licensed under a Creative Commons Attribution 4.0 International License, which permits use, sharing, adaptation, distribution and reproduction in any medium or format, as long as you give appropriate credit to the original author(s) and the source, provide a link to the Creative Commons licence, and indicate if changes were made. The images or other third party material in this article are included in the article's Creative Commons licence, unless indicated otherwise in a credit line to the material. If material is not included in the article's Creative Commons licence and your intended use is not permitted by statutory regulation or exceeds the permitted use, you will need to obtain permission directly from the copyright holder. To view a copy of this licence, visit http://creativecommons.org/licenses/by/4.0/.

\section{References}

Bruhn M, Schoenmueller V, Schäfer DB (2012) Are social media replacing traditional media in terms of brand equity creation? Management
Research Review 35(9):770-790. https://doi.org/10.1108/ 01409171211255948

Boudreau, M. C., Gefen, D., \& Straub, D. W. (2001). Validation in information systems research: A state-of-the-art assessment. MIS Quarterly 25(1):1-16.

Chen, J., Teng, L., Yu, Y., \& Yu, X. (2016). The effect of online information sources on purchase intentions between consumers with high and low susceptibility to informational influence. Journal of Business Research, 69(2), 467-475.

Cheong, H. J., \& Morrison, M. A. (2008). Consumers' reliance on product information and recommendations found in UGC. Journal of Interactive Advertising, 8(2), 38-49.

Cheung, C. M., \& Thadani, D. R. (2012). The impact of electronic wordof-mouth communication: A literature analysis and integrative model. Decision support systems, 54(1), 461-470.

Cheung, M. Y., Luo, C., Sia, C. L., \& Chen, H. (2009). Credibility of electronic word-of-mouth: Informational and normative determinants of on-line consumer recommendations. International Journal of Electronic Commerce, 13(4), 9-38.

Chevalier, J. A., \& Mayzlin, D. (2006). The effect of word of mouth on sales: Online book reviews. Journal of Marketing Research, 43(3), $345-354$.

Chiu, C. M., Wang, E. T., Fang, Y. H., \& Huang, H. Y. (2014). Understanding customers' repeat purchase intentions in B2C e-commerce: the roles of utilitarian value, hedonic value and perceived risk. Information Systems Journal, 24(1), 85-114.

Croson, R., Schultz, K., Siemsen, E., \& Yeo, M. (2013). Behavioral operations: the state of the field. Journal of Operations Management, 31(1-2), 1-5.

de Guinea, A. O., Titah, R., \& Léger, P.-M. (2014). Explicit and implicit antecedents of users' behavioral beliefs in information systems: A neuropsychological investigation. Journal of Management Information Systems, 30(4), 179-210.

Dhar, V., \& Chang, E. A. (2009). Does chatter matter? The impact of user-generated content on music sales. Journal of Interactive Marketing, 23(4), 300-307.

Di Stasi, L. L., Catena, A., Canas, J. J., Macknik, S. L., \& MartinezConde, S. (2013). Saccadic velocity as an arousal index in naturalistic tasks. Neuroscience \& Biobehavioral Reviews, 37(5), 968-975.

Dimoka, A., Davis, F. D., Gupta, A., Pavlou, P. A., Banker, R. D., Dennis, A. R.,... Gefen, D. (2012). On the use of neurophysiological tools in IS research: Developing a research agenda for NeuroIS. MIS Quarterly, 679-702.

Dimoka, A., Pavlou, P. A., \& Davis, F. D. (2011). Research commentary-NeuroIS: The potential of cognitive neuroscience for information systems research. Information Systems Research, 22(4), $687-702$.

Duchowski, A. T. (2007). Eye tracking methodology. Theory and Practice, 328.

Dwivedi, Y. K., Kelly, G., Janssen, M., Rana, N. P., Slade, E. L., \& Clement, M. (2018). Social Media: The good, the bad, and the ugly. Information Systems Frontiers, 20(3), 419-423.

Dwivedi, Y. K., Williams, M. D., \& Venkatesh, V. (2008). Guest Editorial: A profile of adoption of Information \& Communication Technologies (ICT) research in the household context. Information Systems Frontiers, 10(4), 385.

Engbert, R., Nuthmann, A., Richter, E. M., \& Kliegl, R. (2005). SWIFT: a dynamical model of saccade generation during reading. Psychological review, 112(4), 777.

Filieri, R. (2015). What makes online reviews helpful? A diagnosticityadoption framework to explain informational and normative influences in e-WOM. Journal of Business Research, 68(6), 1261-1270.

Flanagin, A. J., \& Metzger, M. J. (2013). Trusting expert-versus usergenerated ratings online: The role of information volume, valence, and consumer characteristics. Computers in Human Behavior, 29(4), 1626-1634. 
Flanagin, A. J., Metzger, M. J., Pure, R., Markov, A., \& Hartsell, E. (2014). Mitigating risk in ecommerce transactions: perceptions of information credibility and the role of user-generated ratings in product quality and purchase intention. Electronic Commerce Research, 14(1), 1-23.

Flores, W., Chen, J.-C. V., \& Ross, W. H. (2014). The effect of variations in banner ad, type of product, website context, and language of advertising on Internet users' attitudes. Computers in Human Behavior, 31, 37-47.

Forman, C., Ghose, A., \& Wiesenfeld, B. (2008). Examining the relationship between reviews and sales: The role of reviewer identity disclosure in electronic markets. Information Systems Research, 19(3), 291-313.

Goh, K.-Y., Heng, C.-S., \& Lin, Z. (2013). Social media brand community and consumer behavior: Quantifying the relative impact of userand marketer-generated content. Information Systems Research, 24(1), 88-107.

Hyönä, J., Tommola, J., \& Alaja, A.-M. (1995). Pupil dilation as a measure of processing load in simultaneous interpretation and other language tasks. The Quarterly Journal of Experimental Psychology, 48(3), 598-612.

Jacob, R. J., \& Karn, K. S. (2003). Eye tracking in human-computer interaction and usability research: Ready to deliver the promises. In The mind's eye (pp. 573-605). Amsterdam: Elsevier.

Just, M. A., \& Carpenter, P. A. (1980). A theory of reading: From eye fixations to comprehension. Psychological review, 87(4), 329.

Kahneman, D., Tursky, B., Shapiro, D., \& Crider, A. (1969). Pupillary, heart rate, and skin resistance changes during a mental task. Journal of experimental psychology, 79(1p1), 164.

Kapoor, K. K., Tamilmani, K., Rana, N. P., Patil, P., Dwivedi, Y. K., \& Nerur, S. (2018). Advances in social media research: Past, present and future. Information Systems Frontiers, 20(3), 531-558.

Kaushik, K., Mishra, R., Rana, N. P., \& Dwivedi, Y. K. (2018). Exploring reviews and review sequences on e-commerce platform: A study of helpful reviews on Amazon. in. Journal of retailing and Consumer Services, 45, 21-32.

Kim, J., Fiore, A. M., \& Lee, H.-H. (2007). Influences of online store perception, shopping enjoyment, and shopping involvement on consumer patronage behavior towards an online retailer. Journal of retailing and Consumer Services, 14(2), 95-107.

Kim, M., \& Lennon, S. (2008). The effects of visual and verbal information on attitudes and purchase intentions in internet shopping. Psychology \& Marketing, 25(2), 146-178.

Kim, Y., \& Srivastava, J. (2007). Impact of social influence in ecommerce decision making. Paper presented at the Proceedings of the ninth international conference on Electronic commerce.

Kizgin, H., Jamal, A., Dey, B. L., \& Rana, N. P. (2018). The impact of social media on consumers' acculturation and purchase intentions. Information Systems Frontiers, 20(3), 503-514.

Ko, H., Cho, C.-H., \& Roberts, M. S. (2005). Internet uses and gratifications: A structural equation model of interactive advertising. Journal of advertising, 34(2), 57-70.

Lee, J., Park, D.-H., \& Han, I. (2008). The effect of negative online consumer reviews on product attitude: An information processing view. Electronic commerce research and applications, 7(3), 341352.

Léger, P.-M., Sénecal, S., Courtemanche, F., de Guinea, A. O., Titah, R., Fredette, M., \& Labonte-LeMoyne, É (2014). Precision is in the eye of the beholder: Application of eye fixation-related potentials to information systems research.

Liang, T.-P., \& Turban, E. (2011). Introduction to the special issue social commerce: a research framework for social commerce. International Journal of Electronic Commerce, 16(2), 5-14.

Lilliefors, H. W. (1967). On the Kolmogorov-Smirnov test for normality with mean and variance unknown. Journal of the American statistical Association, 62(318), 399-402.
Limayem, M., \& Cheung, C. M. (2011). Predicting the continued use of Internet-based learning technologies: the role of habit. Behaviour \& Information Technology, 30(1), 91-99.

Lin, X., Featherman, M., Brooks, S. L., \& Hajli, N. (2019). Exploring gender differences in online consumer purchase decision making: An online product presentation perspective. Information Systems Frontiers, 21(5), 1187-1201.

Luan, J., Yao, Z., Zhao, F., \& Liu, H. (2016). Search product and experience product online reviews: an eye-tracking study on consumers' review search behavior. Computers in Human Behavior, 65, 420 430.

Luo, X., Zhang, J., \& Duan, W. (2013). Social media and firm equity value. Information Systems Research, 24(1), 146-163.

McGregor, D. K., \& Stern, J. A. (1996). Time on task and blink effects on saccade duration. Ergonomics, 39(4), 649-660.

Mele, M. L., \& Federici, S. (2012). Gaze and eye-tracking solutions for psychological research. Cognitive processing, 13(1), 261-265.

Mikalef, P., Giannakos, M., \& Pateli, A. (2013). Shopping and word-ofmouth intentions on social media. Journal of theoretical and applied electronic commerce research, 8(1), 17-34.

Mikalef, P., Giannakos, M. N., \& Pappas, I. O. (2017a). Designing social commerce platforms based on consumers' intentions. Behaviour \& Information Technology, 36(12), 1308-1327.

Mikalef, P., Giannakos, M. N., \& Pateli, A. G. (2012). Exploring the Business Potential of Social Media: An Utilitarian and Hedonic Motivation Approach. Paper presented at the Bled eConference.

Mikalef, P., Pappas, I. O., \& Giannakos, M. (2016). Consumer Intentions on Social Media: A fsQCA Analysis of Motivations. Paper presented at the Conference on e-Business, e-Services and e-Society.

Mikalef, P., Pappas, I. O., \& Giannakos, M. N. (2017b). Value cocreation and purchase intention in social commerce: The enabling role of word-of-mouth and trust. Paper presented at the AMCIS.

Mikalef, P., Sharma, K., Pappas, I. O., \& Giannakos, M. N. (2017c). Online Reviews or Marketer Information? An Eye-Tracking Study on Social Commerce Consumers. Paper presented at the Conference on e-Business, e-Services and e-Society.

Muhammad, S. S., Dey, B. L., \& Weerakkody, V. (2018). Analysis of factors that influence customers' willingness to leave big data digital footprints on social media: A systematic review of literature. Information Systems Frontiers, 20(3), 559-576.

Myers, M. D., \& Newman, M. (2007). The qualitative interview in IS research: Examining the craft. Information and organization, 17(1), $2-26$.

Nyström, M., Hooge, I., \& Andersson, R. (2016). Pupil size influences the eye-tracker signal during saccades. Vision research, 121, 95103.

Pappas, I., Mikalef, P., Giannakos, M., \& Pavlou, P. (2017). Value cocreation and trust in social commerce: An fsQCA approach.

Pappas, I., Sharma, K., Mikalef, P., \& Giannakos, M. (2018). Visual aesthetics of E-commerce websites: An eye-tracking approach.

Plume, C. J., \& Slade, E. L. (2018). Sharing of sponsored advertisements on social media: A uses and gratifications perspective. Information Systems Frontiers, 20(3), 471-483.

Priebe, J., Messingschlager, M., \& Lautenbacher, S. (2015). Gaze behaviour when monitoring pain faces: An eye-tracking study. European Journal of Pain, 19(6), 817-825.

Roma, P., \& Aloini, D. (2019). How does brand-related user-generated content differ across social media? Evidence reloaded. Journal of Business Research, 96, 322-339.

Ruggiero, T. E. (2000). Uses and gratifications theory in the 21 st century. Mass communication \& society, 3(1), 3-37.

Salvucci, D. D., \& Goldberg, J. H. (2000). Identifying fixations and saccades in eye-tracking protocols. Paper presented at the Proceedings of the 2000 symposium on Eye tracking research \& applications. 
Saumya, S., Singh, J. P., Baabdullah, A. M., Rana, N. P., \& Dwivedi, Y. K. (2018). Ranking online consumer reviews. Electronic commerce research and applications, $29,78-89$.

Shapiro, S. S., \& Francia, R. (1972). An approximate analysis of variance test for normality. Journal of the American statistical Association, 67(337), 215-216.

Singh, J. P., Irani, S., Rana, N. P., Dwivedi, Y. K., Saumya, S., \& Roy, P. K. (2017). Predicting the "helpfulness" of online consumer reviews. Journal of Business Research, 70, 346-355.

Stephen, A. T., \& Toubia, O. (2010). Deriving value from social commerce networks. Journal of Marketing Research, 47(2), 215-228.

Tang, H., Lee, C. B. P., \& Choong, K. K. (2017). Consumer decision support systems for novice buyers-a design science approach. Information Systems Frontiers, 19(4), 881-897.

Trusov, M., Bucklin, R. E., \& Pauwels, K. (2009). Effects of word-ofmouth versus traditional marketing: findings from an internet social networking site. Journal of marketing, 73(5), 90-102.

Tsai, W.-H. S., \& Men, L. R. (2017). Consumer engagement with brands on social network sites: a cross-cultural comparison of China and the USA. Journal of Marketing Communications, 23(1), 2-21.

Van Dijck, J. (2009). Users like you? Theorizing agency in usergenerated content. Media, culture \& society, 31(1), 41-58.

Vourvopoulos, A., Niforatos, E., \& Giannakos, M. (2019). EEGlass: An EEG-eyeware prototype for ubiquitous brain-computer interaction. Paper presented at the Adjunct Proceedings of the 2019 ACM International Joint Conference on Pervasive and Ubiquitous Computing and Proceedings of the 2019 ACM International Symposium on Wearable Computers.

Wang, Y., \& Yu, C. (2017). Social interaction-based consumer decisionmaking model in social commerce: The role of word of mouth and observational learning. International Journal of Information Management, 37(3), 179-189.

Wells, J. D., Valacich, J. S., \& Hess, T. J. (2011). What signal are you sending? How website quality influences perceptions of product quality and purchase intentions. MIS quarterly, 35(2), 373-396.
Yadav, M. S., De Valck, K., Hennig-Thurau, T., Hoffman, D. L., \& Spann, M. (2013). Social commerce: a contingency framework for assessing marketing potential. Journal of Interactive Marketing, 27(4), 311-323.

Ye, Q., Law, R., Gu, B., \& Chen, W. (2011). The influence of usergenerated content on traveler behavior: An empirical investigation on the effects of e-word-of-mouth to hotel online bookings. Computers in Human Behavior, 27(2), 634-639.

Yin, R. K. (2017). Case study research and applications: Design and methods. Thousand Oaks: Sage publications.

Yoo, J., \& Kim, M. (2014). The effects of online product presentation on consumer responses: A mental imagery perspective. Journal of Business Research, 67(11), 2464-2472.

Zhang, K. Z., \& Benyoucef, M. (2016). Consumer behavior in social commerce: A literature review. Decision support systems, 86, 95108.

Zhang, M. J. (2005). Information systems, strategic flexibility and firm performance: an empirical investigation. Journal of Engineering and Technology Management, 22(3), 163-184.

Zheng, C., Yu, X., \& Jin, Q. (2017). How user relationships affect user perceived value propositions of enterprises on social commerce platforms. Information Systems Frontiers, 19(6), 1261-1271.

Zhou, L., Zhang, P., \& Zimmermann, H.-D. (2013). Social commerce research: An integrated view. Electronic commerce research and applications, 12(2), 61-68.

Zhu, F., \& Zhang, X. (2010). Impact of online consumer reviews on sales: The moderating role of product and consumer characteristics. Journal of marketing, 74(2), 133-148.

Publisher's Note Springer Nature remains neutral with regard to jurisdictional claims in published maps and institutional affiliations. 